\title{
La programación deportiva ¿qué lugar ocupan las mujeres?
}

\author{
Judit Martínez Abajo' (iD 0000-0002-8414-9819 \\ Gema Lasarte Leonet $^{2}$ (iD) 0000-0002-8362-6142 \\ Rakel Gamito Gomez ${ }^{3}$ \\ $0000-0002-2972-8025$ \\ María Teresa Vizcarra Morales ${ }^{1}$ \\ 0000-0002-9369-9740
}

'Universidad del País Vasco (UPV/EHU), Facultad de Educación y Deporte, Departamento de Didáctica de la Expresión Musical, Plástica y Corporal, Vitoria-Gasteiz, España, 01006.

${ }^{2}$ Universidad del País Vasco (UPV/EHU), Facultad de Educación y Deporte, Departamento de Didáctica de la Lengua y la Literatura, Vitoria-Gasteiz, España, 01006. 3Universidad del País Vasco (UPV/EHU), Facultad de Educación y Deporte, Departamento de Didáctica y Organización Escolar, Vitoria-Gasteiz, España, 01006.

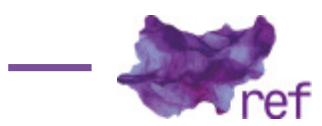

\begin{abstract}
Resumen: Este artículo tiene como objetivo principal describir la percepción de las deportistas sobre la programación deportiva y, en segundo lugar, identificar si se sienten empoderadas con respecto a los medios de comunicación. Se realizan 19 entrevistas en profundidad y tres focus group con deportistas vascas de élite, 33 en total. Concluyen que la programación deportiva contribuye a visibilizar el deporte masculino (56,38\%). El 19,04\% de las entrevistadas señala la omnipresencia del futbol; $14,28 \%$ apunta, además, la usurpación del espacio mediático en detrimento del deporte femenino cuando la programación prioriza los aspectos no deportivos de las deportistas como casamientos, lesiones etc. Palabras clave: género; empoderamiento; programación deportiva; medios de comunicación.
\end{abstract}

Sports Programming, what Place do Women Occupy?

Abstract: This article describes sportswomen's perception of sports in the media and aims to identify whether mass media empower them. The research work conducted 19 in-depth interviews with three focus groups composed of 33 Basque elite sportswomen. The results indicate that sports media programs contribute to represent men's sports (56.38\%). $19.04 \%$ of the respondents mention that soccer is omnipresent; $14.28 \%$ of the respondents affirm that soccer invades the broadcasting space at the expense of women's sports when the programs give priority to aspects not concerned with those women athletes such as weddings, injuries, and others.

Keywords: Gender; Empowerment; Sports media; Media.

Programação esportiva, que lugar as mulheres ocupam?

Resumo: Este artigo tem como objetivo principal descrever a percepção das desportistas sobre a programação de desporto, e, em segundo lugar, avaliar se se sentem empoderadas em relação à mídia. Realizaram-se 19 entrevistas em profundidade e três focus groups com desportistas de elite bascas, 33 no total. Concluíram que a programação desportiva contribui para dar visibilidade ao desporto masculino (56,38\%). 19,04\% das entrevistadas destacaram a omnipresença do futebol; $14,28 \%$ ressaltaram também a apropriação do espaço mediático em detrimento do desporto feminino quando a programação dá prioridade a aspectos não desportivos das desportistas, como casamentos, lesões, entre outros.

Palavras-chave: gênero; empoderamento; programação esportiva, meios de comunicação. 


\section{Introducción}

El objeto de este estudio es comprender la percepción de las deportistas sobre la programación deportiva en el contexto vasco. La organización del deporte en el País Vasco está regulada por el Gobierno Vasco a través del Departamento de Cultura, pero depende de las diputaciones forales y de las federaciones. Sus líneas de actuación son: la formación, el deporte escolar; el deporte federado; el deporte de alto nivel; la actividad física y el deporte para la salud; la innovación deportiva y la participación; y la colaboración con agentes del deporte a través de distintos organismos, así como la incorporación de la mirada transversal en el deporte, dentro de la que se incluye el "grupo de Trabajo Mujeres y Deporte" (Departamento de Cultura del Gobierno Vasco, 2012, p. 140-141).

Así, la Ley para la Igualdad de mujeres y hombres (2005) pretende compensar desigualdades de género y supone un "punto de inflexión en el marco de las políticas de igualdad en el deporte" (Ainhoa AZURMENDI; Juan MURUA, 2010). En el VII Plan para la lgualdad de Mujeres y hombres en la Comunidad Autónoma del País Vasco (CAPV) (2018-2021) aparece el compromiso de promocionar el deporte femenino (EMAKUNDE, 2018, p. 19). En ese marco se han realizado guías, materiales y talleres en colaboración con la Unión de Federaciones Deportivas Vascas y la Fundación Basqueteam, que se encarga del deporte de alto rendimiento (BASQUETEAM, 2019).

A pesar de la incorporación de las leyes igualatorias y de los logros obtenidos por las deportistas "todavía el deporte es posiblemente, uno de los medios donde el hombre es considerado superior" (Lilian VEGA; María Alejandra ÁVALOS, 2016, p. 169). Las deportistas vascas se enfrentan a obstáculos estructurales y organizacionales, especialmente en el ámbito de las federaciones y clubes, reciben menor apoyo económico, con entrenadores menos cualificados y peores instalaciones (AZURMENDI; MURUA, 2010).

En este sentido, existen muchos estudios de género que han analizado la escasa presencia de las mujeres en la prensa en las últimas décadas (Elida ALFARO, et al. 2011; Marta ANGULO, 2007; ASPIC Asesoría 2013; Clara SAINZ DE BARANDA, 2013), y aunque se advierten ciertos avances, la situación aún no es ideal. En la programación deportiva, en primer lugar, aparece la omnipresencia del futbol, en segundo lugar, otros deportes y por último, el deporte realizado por mujeres (Alina BERNESTEIN, 2002).

La incipiente visibilidad de las deportistas de élite se está consiguiendo gracias a la organización, al empoderamiento y a la lucha de las mujeres (Fe ROBLES, 2019) y este hecho posibilita disertar sobre empoderamiento y sobre agencia. Para empoderarse es necesario la adquisición de agencia, o visibilidad, que se puede ejercer de forma individual o colectiva, que coincide con el término de agency (Sherry ORTNER, 2006).

Existen tres ámbitos donde se pueden evaluar los cambios de agencia (Naila KABEER, 1997), la participación en la toma de decisiones, la movilidad en el ámbito público y la violencia masculina. Así, el primer ámbito de la agencia de las mujeres mejora notablemente cuando éstas tienen voz para expresarse sobre aspectos críticos de su vida, o sobre temas que les fueron vetados en el pasado. Otro indicador (KABEER, 1999) tiene que ver con las localizaciones, de tal forma que la movilidad de las mujeres se convierte en una cartografía de poder o subalternidad, porque existen lugares prohibidos o inadecuados para ellas. Existe un continuum entre los lugares aceptables y los no aceptables para las mujeres (Clara MURGUIALDAY, 2006), y así, los escenarios públicos de competición han sido hegemónicamente masculinos. Esto nos lleva a ver cómo se intercalan la resistencia y la negociación en esas localizaciones ante el poder sustentado por los hombres en la actividad y en la programación deportiva. Fruto de esta conjunción se dará el empoderamiento en la toma decisiones y en la movilidad en el ámbito deportivo.

Distintos análisis culturales feministas subrayan tres modos en la aparición de la mujer en la esfera cultural. Una primera, tímida, emulando el poder masculino; una segunda, de reivindicación y lucha; y una tercera, donde ellas empiezan a crear sus propios estilos y escenarios (Elaine SHOWALTER, 1977). Y esta lectura feminista aparece reflejada en el mundo del deporte vasco (Uxue FERNANDEZ-LASA, 2014).

Cuando se habla de empoderamiento, se habla de las relaciones existentes de poder (Michel FOUCAULT, 1972; Antonio GRAMSCI, 1971; Paulo FREIRE, 1986) y de la necesidad de desafiar estas relaciones de poder existentes para obtener un mayor control (MURGUIALDAY, 2013). Dicho de otra manera, de la necesidad de alteración radical de los procesos y estructuras que reproducen la posición subordinada de las mujeres como género (Peter OAKLEY, 2001). El poder para Foucault no es una sustancia estática que se posee, sino que se ejerce en un entramado histórico de acciones y relaciones sociales: allí donde existe sociedad humana hay relaciones de poder. Así, también donde se ejerce el poder se producen confrontaciones, conflictos y resistencias (Mercedes FERNÁNDEZ, 2012).

El empoderamiento tiene que ver con ganar poder en el colectivo de las desempoderadas (MURGUIALDAY, 2013). En este sentido es interesante la interpretación tripartita de poder elaborada en Power, A radical view de Steven Lukes (1974), que discierne tres caras diferentes del mismo: el 
poder visible, el poder oculto y el poder invisible (gráfico 1). El poder visible se vale de expresiones formales, de las reglas de juego formales de la sociedad, da cuenta de la capacidad o habilidad de las personas o grupos para lograr que otras personas actúen en contra de sus deseos 0 preferencias. El poder oculto se erige en las reglas y el procedimiento que vuelven invisibles a las voces subalternas (intimidación, coerción, desinformación); se trata de una segunda dimensión de la primera. Así, consiste en la capacidad de seleccionar qué aspectos se toman en cuenta en la toma de decisiones y qué otros quedan suprimidos o no se consideran de ninguna manera (Magdalena LEÓN, 1997; MURGIALDAY, 2013). Y por último, el poder invisible fomenta las prácticas y las normas culturales que disuaden a la gente para actuar hacia el cambio. Los grupos excluidos interiorizan sentimientos de apatía, sumisión y culpabilidad (MURGUIALDAY, 2006). Las mujeres son sujeto de subordinación en las dos primeras dimensiones, ya que se les niega o limita el acceso a la gestión económica y política que mantiene la asimetría de género; pero la interiorización subjetiva de valores, normas y prácticas desempeñan un papel restrictivo fundamental en la ocultación de la dominación masculina de la que habla Pierre Bourdieu (2000) y en la reducción de los conflictos entre hombres y mujeres. El análisis tridimensional de Lukes nos sitúa en diferentes niveles de análisis (global, regional, nacional, familiar...) y en distintas esferas: física, sociocultural, religiosa, política... (LEÓN, 1997). Gracias a esta especificación en las investigaciones se localiza mejor el lugar de subordinación de la mujer. Según este razonamiento, nuestra investigación se ubica dentro de los poderes visible y ocultos y en la esfera socio/cultural.

Para contrarrestar las tres formas de poder y afrontar el desempoderamiento y la exclusión (MURGUIALDAY, 2006) se plantean distintas estrategias. Así, para enfrentarse al poder visible, se enfatiza la necesidad de ganar poder para cambiar la realidad. Este tipo de poder tiene que ver con la agencia.

Para acceder a esta dimensión políica del empoderamiento las mujeres han de actuar colectivamente en la arena pública tomando parte en todos los ámbitos donde se toman decisiones relevantes para ellas y sus colectivos de pertenencia. (MURGIALDAY, 2013, p. 37)

Hay que señalar que la relevancia y el interés de este artículo se centra en poner en la boca de las protagonistas los sentimientos vividos a través de sus propias experiencias para no seguir repitiendo la misma historia de siempre (David KIRK; Kimberly OLIVER, 2014) ya que en los estudios realizados hasta ahora faltan por recoger las opiniones de estas protagonistas. En la presente investigación se van a estudiar algunos de los fenómenos sociales donde el sistema patriarcal está presente, y se va a analizar cuáles son los factores que hacen que este sistema se mantenga porque los avances logrados hasta el momento que han sido gracias al trabajo de las deportistas (Begoña MARUGÁN, 2017).

\section{Medios de comunicación y género}

La presencia de las mujeres en los medios de comunicación es escasa, irreal y desequilibrada, pocas veces aparecen las mujeres y cuando lo hacen suelen hacerlo en secciones con menor importancia, tales como cultura o sociedad, no en secciones consideradas más importantes como economía o política (Joana GALLEGO; Elvira ALTÉS; María Elvira MELÚS; Jaume SORIANO; María José CANTÓN, 2002). Resulta llamativa la falta de conciencia y de voluntad política expresada en desinterés y escaso espacio en los medios de comunicación (lbone LALLANA, 2012).

No existimos. Ni en los medios de comunicación, ni en las presidencias de las federaciones. El techo de cristal del deporte español es un armazón de cemento compuesto de mucho patriarcado y mucho territorio de donde las mujeres hemos sido excluidas. Y abrirse a la igualdad, exige que muchos puestos de los que disfrutan por inercia sean para las mujeres e incluyan una perspectiva de género en todas las políticas deportivas. (Mar MÁS, 2019, p. 188)

Asumir las diferencias de género y formular un discurso periodístico desde este convencimiento no es sencillo, como no lo es constatar que las diferencias de género siguen existiendo, por más que la educación y la evolución social hayan aproximado sus usos y costumbres (GALLEGO et al., 2002). No es sencillo, pero sí necesario, que los medios de comunicación contribuyan de forma decisiva a una didáctica social dirigida a eliminar ese tipo de desigualdad "y al buen uso de los mismos para contribuir a sociedades más equitativas" (VEGA; ÁVALOS, 2016, p. 1).

Antes de revisar los estudios realizados en torno a la presencia de las mujeres en la programación deportiva, hay que subrayar la importancia de la participación de las desempoderadas en las instancias de poder (KABEER, 1999). Se debe impulsar el acceso de las mujeres a puestos de decisión en empresas relacionadas con los medios de comunicación, crear centros de supervisión de los medios y se debe incluir la perspectiva de género en la formación de periodistas (MÁS, 2019).

Hay que propiciar la reflexión sobre la existencia de los géneros... y la consiguiente asunción de un tratamiento progresivo de los temas con perspectiva de género, que sería la cristalización 
profesional del reconocimiento de las diferencias de género. La perspectiva de género no implica realizar un periodismo feminista, sino un periodismo basado en la evidencia de las diferencias debido al género y en otorgar a esa diferencia un significado y un lugar en el discurso informativo, lugar del que en la actualidad carece. (GALLEGO et al., 2002, p. 239)

En este sentido, los estudios previos consultados muestran que en Europa se habla de una presencia de las mujeres deportistas en la prensa cercana al $25 \%$, mientras que en un estudio realizado por el Gobierno Vasco (España) con la asesoría ASPIC (2013) se habla de una presencia femenina no superior al 5,9\%. Y así, Susana IRAZUSTA et al. (2012) mostraron que la presencia de la mujer es menor en la prensa escrita. Un momento puntual de impulso a la imagen deportista fueron los resultados en los Juegos Olímpicos (JJOO) de Londres (2012), que ayudaron a la visualización de la mujer en este ámbito (Begoña SANZ, 2015).

En el deporte de alto nivel, los datos de participación entre mujeres y hombres están bastante equilibrados, las mayores diferencias de participación se ven en el deporte de base:

La participación en el alto rendimiento, tomando el total de deportistas, es de un $57 \%$ de hombres, frente a un $43 \%$ de mujeres. En el deporte escolar del total de practicantes tan solo el $30 \%$ eran niñas. En el deporte federado de base solo el 16,2\% son mujeres. En la gestión del deporte federado solo un $7 \%$ son mujeres. (ANGULO, 2007, p. 2)

En la sociedad de la información los medios manipulan el pensamiento porque fabrican y controlan las ideas (Yolanda HERRÁNZ, 2006) de tal manera que influyen en la manera de ver la realidad, así como en las expectativas. Los gustos por determinados deportes son construidos, y nos generan unas determinadas necesidades. Además, los mensajes son sexistas y contribuyen a fomentar el estereotipo de mujer objeto de consumo y un estereotipo masculino relacionado con determinadas prácticas deportivas, donde la mujer es la eterna ausente (María Teresa VIZCARRA; Ana MACAZAGA; Itziar REKALDE, 2009). La prensa ofrece una imagen de las mujeres que no coincide con la realidad social que se vive cotidianamente, apenas aparecen fotografías de mujeres deportistas. En un estudio realizado por María Flora Marín y María Ganzabal (201 1), se analizó esta presencia en las fotografías de los periódicos EI País y EI Mundo, recogiendo que tan solo aparecían mujeres como protagonistas en un $14 \%$. Además, cuando las mujeres aparecían en la prensa, solían tener un papel pasivo, a la sombra de los hombres.

La no presencia de la mujer deportista en la prensa se toma como algo natural, por lo que las personas responsables de estos medios justifican dicha ausencia afirmando que no es un asunto de interés para el público en general (José Luis ROJAS, 2010). Sin embargo, la presencia del hombre en la prensa deportiva es casi hegemónica. En otro análisis realizado por Sainz de Baranda (2013), los hombres fueron protagonistas en un $91 \%$ de las noticias. Esta ausencia convierte a la mujer en sujeto ausente, lo que no se ve, no se conoce, no se aprecia, no existe (Pilar LÓPEZ, 2005). En el estudio realizado sobre la presencia de las mujeres en la televisión española (VEGA; ÁVALOS, 2016), se afirmó que los tres canales más vistos en España (TVE, Tele 5 y Antena 3) emitían en su programación el mismo número de noticias deportivas. De esta emisión de noticias, el $80 \%$ se relacionaba con los deportistas, y el $20 \%$ con las deportistas. La televisión pública emitió un 56,66 $\%$ relacionado con el deporte masculino y $43,33 \%$ con el femenino. A diferencia de Tele 5 y Antena 3 , que ofrecieron un $86,66 \%$, y un $96,66 \%$ de deporte masculino respectivamente, y frente al $13,33 \%$ y $3,3 \%$ de deporte femenino. Pero este dato que coloca en una posición privilegiada a la televisión pública se ve desmontado cuando el mismo estudio señala los tiempos de emisión de cada cadena. Durante 30 días que duró el estudio, la población española consumió en estas cadenas $8 \mathrm{~h} \mathrm{16}$ ' 31 " de deporte, y de este cómputo sólo aparecieron las mujeres deportistas en $23^{\prime} 15 "$. Dicho estudio se realizó en vísperas de los JJOO de Brasil en 2016. En dichas Olimpiadas brasileñas, la delegación española estuvo representada por 143 mujeres y 163 hombres. Cuatro de los siete oros logrados fueron en el deporte femenino. Las mujeres en total obtuvieron 17 medallas olímpicas en Río, lo que supuso el $53 \%$ de los metales obtenidos por la representación española, mientras que su presencia en la prensa solo fue del $23 \%$.

Los logros de las mujeres en el deporte son tan buenos como los de los hombres, y en algunas modalidades son incluso mejores, como se puede ver en el ejemplo de las Olimpiadas de Brasil; pero a pesar de ello, no consiguen hacerse un hueco en los medios de comunicación. La mayor parte de la prensa deportiva se ocupa con las modalidades masculinas de dos ó tres deportes solamente, lo que lleva consigo mucha desigualdad, ya que, al dar mayor espacio en los medios a determinados deportistas, se les estará quitando espacio a las mujeres y a otras modalidades. Además, los medios de comunicación utilizan un lenguaje sexista que invisibiliza a Ias mujeres y sus logros, y que acalla sus voces (ANGULO, 2007; Susana GUERRERO, 2017).

\section{La importancia del empoderamiento ante la programación deportiva}

Mientras las mujeres acceden a puestos de poder, han comenzado a organizarse con el objetivo de lograr la profesionalización del deporte femenino y su visibilización. Hay varios motivos 
que explican la creación de asociaciones de mujeres deportistas; por una parte responde a los logros de las deportistas en los últimos años y por otra, la aparición de internet y las redes sociales. "Su aparición fue el lugar idóneo para el empoderamiento femenino, que dejó de depender de los medios tradicionales, para mostrar sus logros y sus deportes" (ROBLES, 2019, p. 185). En este sentido, la jugadora de baloncesto Elisa Aguilar afirma:

Tenemos que ser conscientes que no podemos dejar que los demás vengan a solucionar nuestros problemas. Las deportistas tenemos que coger las riendas de nuestros intereses y todo empieza por hacer valer nuestros puestos de trabajo y no todo vale por jugar en un club. Y para ello necesitamos estar más unidas y más comprometidas. (en María José LÓPEZ, 2017, p.169)

Desde la Asociación para Mujeres en el Deporte Profesional (AMDP) han formulado una hoja de ruta para el cambio de paradigma en el deporte, entre sus puntos se encuentra luchar por: una nueva ley del deporte, $50 \%$ de cuota de pantalla en RTVE, Estatuto del deportista y periodismo con perspectiva de género (MÁS, 2019).

Para confrontar el poder oculto, se percibe la necesidad de que las mujeres puedan transitar del 'yo' al 'nosotras' (Sarah MOSEDALE, 2005), y hablar necesariamente de la identidad colectiva. Para la creación de esta identidad colectiva se necesitan condiciones favorables, espacios sociales donde las mujeres puedan sentirse seguras y valoradas, redes que puedan permitir expandir las nuevas visiones, respuestas sociales a su nueva identidad que fuercen a cada mujer a confrontar las creencias heredadas (MURGUIALDAY, 2013). Y por último, para posicionarse frente a la invisibilización, la mujer necesita adquirir poder interno. Cada una debe fortalecerse personalmente y ser consciente de que vive una subordinación, y esta reflexión sobre la subordinación femenina será el paso inicial hacia el empoderamiento. En primer lugar, será una labor interna; en segundo lugar, este poder interno se socializará y se compartirá mediante el reconocimiento e integración de las experiencias internas y externas. Y finalmente, en el último eslabón se hablará de la capacidad de incidencia política y del poder para el cambio.

En esta última fase de empoderamiento, el feminismo vislumbra la capacidad de resistencia y transformación del poder controlador o de dominación, concibe así a las mujeres como agentes individuales y como colectivo con capacidades y competencias que, aunque estén restringidas socialmente, no necesitan ser salvadas por otras personas, colectivos o instituciones desde una posición superior (María Teresa BLANDÓN; MURGUIALDAY; Norma VÁZQUEZ, 2011). Se necesita, reflexionar, descodificar la interiorización de la subordinación femenina; desarrollar "mentes críticas", y se requiere un espacio de reflexión, de discusión e intercambio de experiencias. Esta reflexión conjunta y compartida conlleva el fortalecimiento de recursos internos como la autoestima, la autoimagen y la confianza en sí mismas (FERNÁNDEZ, 2012).

Todo este proceso de empoderamiento se relaciona con la agencia y con las elecciones que se llevan a cabo (KABEER, 1999) y con la capacidad de hacer elecciones vitales estratégicas. Se trata de ver que hay alternativas a lo elegido, que las voces subalternas perciben claramente su situación de subordinación y asimismo la posibilidad de cambio (Gayatri Chakravorty SPIVAK, 1993). Se propone ver a las mujeres no como víctimas sino como agentes de sus vidas (Mari Luz ESTEBAN, 2011 ). Esta visión no victimista ya se recoge en investigaciones anteriores (Dolores JULIANO, 1992; 1998), a modo de ejemplo, las Madres de la Plaza de Mayo son vistas como agentes y madres empoderadas. Entre las distintas acepciones del empoderamiento, se subrayan los conceptos de agencia y resistencia, que son claves en el marco empírico de este artículo. Se afirma que el poder adquiere múltiples formas,

que no es exclusivamente una relación dicotómica entre dominados y dominadores y no siempre opera a través de la represión, la vigilancia, el control o la prohibición, sino a través del deseo y la creación. Por tanto, el poder no siempre es represivo o controlador, ni las prácticas individuales y colectivas están sobredeterminadas o constreñidas de modo absoluto. (FERNÁNDEZ, 2012, p. 12)

La acción creativa y transformadora tienen cabida en la práctica humana (FERNÁNDEZ, 1996), aún dentro de las restricciones impuestas socialmente, "una regulación que es inseparable de la capacidad de agencia y resistencia que tienen todos y cada uno de los individuos, sea cual sea su posición social" (ESTEBAN, 2011, p. 49).

Los objetivos del presente artículo son: Describir cómo perciben ellas el género en la programación deportiva. Percibir si las mujeres deportistas de élite se sienten empoderadas con respecto a los medios de comunicación.

\section{Método}

Se trata de un estudio de caso que recoge las vivencias y percepciones de las mujeres deportistas vascas con respecto a su visibilidad social y mediática. La aproximación y selección de las deportistas es intencional y fueron elegidas por ser consideradas las informantes más adecuadas para el objetivo del estudio. Se considera un caso único, porque a todas las vivencias 
les atraviesa el mismo fenómeno social (Phil WOOD; Joan SMITH, 2018) de invisibilidad y menosprecio mediático, independientemente del deporte practicado, al ser un fenómeno único se corresponde con un estudio de caso particularista y descriptivo, aunque sea hecho con un colectivo (Gloria PÉREZ SERRANO, 2014; Robert STAKE, 2005).

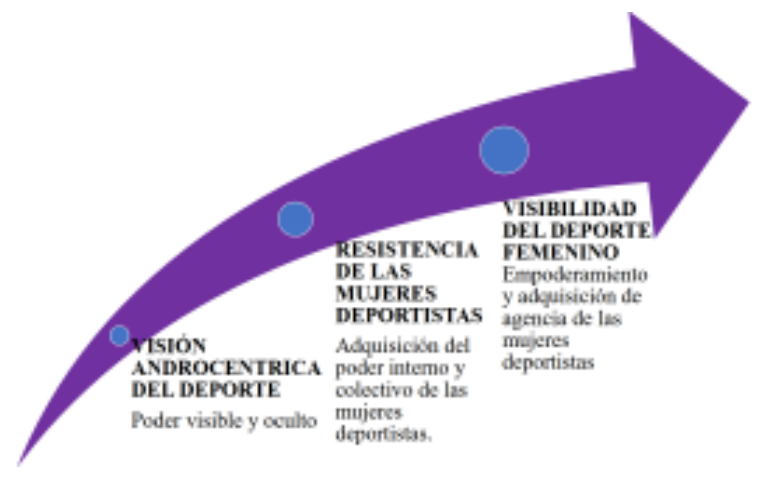

Gráfico 1 - Tránsito de una programación deportiva androcéntrica a una andrógina.

Fuente: elaboración propia a partir de los conceptos de Lukes (1974).

\#PraTodoMundoVer El empoderamiento de las deportistas se representa mediante una flecha que va en crescendo desde un vértice inicial donde las mujeres inician su andadura desde una visión androcéntrica donde el poder visible de los hombres invisibiliza y amedrenta a las mujeres para enfrentarse abiertamente al poder hegemónico, en un segundo estadio la flecha se ensancha al igual que el empoderamiento y sube hacia arriba y aparece la resistencia de las mujeres deportistas, una resistencia que se enfrenta al poder por vez primera y que tiene como fruto un poder interno, una incipiente autoconciencia y la socialización o colectivización de esa conciencia y por último, en el último estadio de la flecha en lo más alto y grueso se halla el empoderamiento de las mujeres deportistas. La adquisición de la agencia. Las mujeres deportistas se convierten en sujetos de su narrativa y visibilizan el deporte femenino.

\section{Partlcipantes e Instrumentos para la recogida de Información}

Para seleccionar las personas a entrevistar se tuvo en cuenta que fueran deportistas del más alto nivel en sus respectivos deportes y que compitieran en el País Vasco y Navarra (España). La elección de la muestra fue intencional, pensando en que eran las interlocutoras más idóneas para este cometido, nos dirigimos a ellas directamente o gracias al efecto de "bola de nieve", donde unas informantes nos llevaron a otras. Se les solicitó el consentimiento informado antes de realizar las entrevistas y se les devolvió la interpretación realizada con sus voces, antes de publicar los resultados de la investigación, para que corroboraran que coincidían con lo expresado. Se realizaron 19 entrevistas en profundidad y 3 focus groups que fueron elegidos a propuesta de las personas entrevistadas y de las personas responsables del Basqueteam. Participaron: tres futbolistas, tres pelotaris, y representantes de diferentes deportes (kárate, lucha, curling, atletismo, balonmano, sokatira, ciclismo, triatlón, surf, automovilismo, esquí y remo). En los focus groups disertaron un total de 16 personas de pelota vasca, remo y fútbol. Un total de 33 deportistas dan voz a esta investigación.

La entrevista en profundidad, según Steinar Kvale (2012) es una interacción profesional que va más allá del intercambio de ideas, y cuyo propósito es obtener conocimiento meticulosamente comprobado. A través de la entrevista se intentará entender asuntos de la vida cotidiana desde la perspectiva propia de cada deportista, para construir conocimiento.

Los focus groups se realizaron para retomar aquellas cuestiones que no habían aparecido en las entrevistas, o para poner en contraste ante el colectivo las percepciones sobre un hecho vivido, y poder comprobar cómo justificaban los desacuerdos, generando una interacción entre las participantes para poder triangular la información. La persona investigadora estimuló la interacción del grupo e hizo el seguimiento (Rosaline BARBOUR, 2013).

\section{Procedimiento en el análisis de la información}

El análisis de la información recogida se ha realizado a través del programa digital de tratamiento de textos NVivo 11 plus, gracias a la construcción de un sistema categorial (ver tabla 1) de carácter inductivo-deductivo. Las categorías son deductivas porque estaban apoyadas en las teorías previas de Showalter (1977), de López (2017), de Luke (1974) y de Murguialday (2013), e inductivas porque recogían también categorías surgidas de los testimonios. Una vez codificadas y categorizadas las referencias se establecieron relaciones jerárquicas entre las diferentes categorías. Se realizó un análisis de contenido por pares, el $n^{\circ}$ de veces que aparecen referencias a cada categoría queda recogido en la tabla. El $n^{\circ}$ total de referencias es de 166 y de ahí salen el porcentaje de aparición de referencias en cada categoría (que solo aporta un dato más, pero no es lo más interesante del artículo). Los análisis realizados por diferentes investigadoras se triangularon en la opción que ofrece la propia herramienta para comparar el índice de coincidencia entre los dos análisis realizados, donde la coincidencia fue de $\mathrm{K}=.76$ al aplicar el 
índice Kappa de Cohen. Los códigos indican la fecha en que se realizó la entrevista (E) o el focus group (FG), y el número siguiente corresponde con cada una de las deportistas de manera aleatoria.

Las categorías y sus límites fueron definidas para que se facilitara todo el proceso hermenéutico. Con la información introducida en NVivol 1 plus, pudimos extraer los sumarios por cada categoría, para posteriormente explicar e interpretar la información clasificada. Las categorías que emergieron de los textos analizados son: visibilidad de ellos (omnipresencia del fútbol, presencia de aspectos superfluos de ellos), lucha de ellas: resistencia (ausencia de las deportistas en la programación y su protesta, difamación, y visibilidad solo cuando hay logros), y la visibilidad de ellas: agencia (las futbolistas presentes en la programación, apertura en la programación y olimpiadas).

\section{Resultados}

A lo largo de las entrevistas realizadas emergen con fuerza tres dimensiones: la hipervisibilidad de ellos (fundamentalmente a través del fútbol) con 66 referencias, la lucha de ellas (su resistencia) con 46 referencias y la visibilidad de ellas a través de su empoderamiento (ellas son agencia) con 18 referencias.

Tabla 1 - Sistema categorial sobre la programación deportiva.

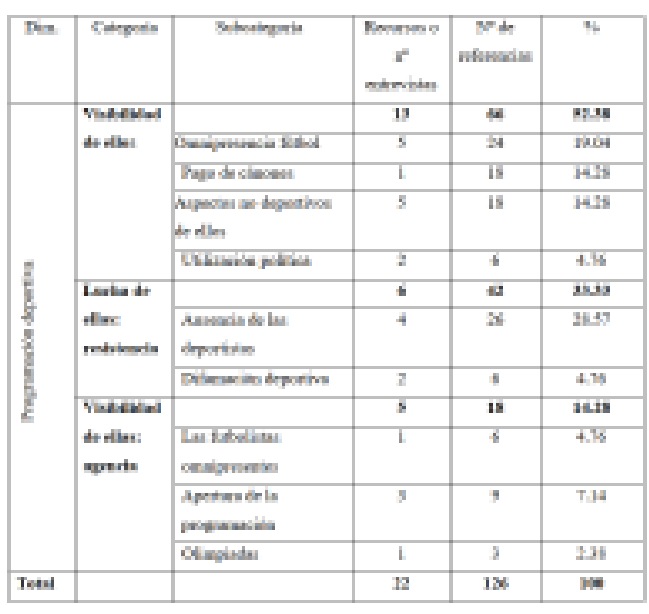

Fuente: elaboración propia.

\#PraTodoMundoVer Se pueden ver tres dimensiones de análisis: la visibilidad de ellos (ellas entienden que esta visibilización se hace a través del futbol en su mayoría y que hay una utilización política de los contenidos deportivos entre otros aspectos); la segunda dimensión c tiene que ver con la lucha de ellas (denuncias ante las difamaciones, denuncian su ausencia en los medios); la tercera dimensión tiene que ver con la visibilidad de ellas (el empoderamiento, el hacerse presentes en las olimpiadas, reclamando abrir la programación...). Los recursos se corresponden con el número de entrevistas en las que aparece alguna mención a cada categoría, y las referencias, al número total de párrafos en los que se habla de una temática, no es el dato más importante del análisis, pero es un dato más.

\section{Visibilidad de ellos}

Esta categoría abarca el 52,38\% de las respuestas recogidas, expresando con ello que la característica principal de la programación deportiva actual según las voces de las personas entrevistadas es que los hombres deportistas ocupan el papel central de la programación con la omnipresencia de un único deporte, el fútbol (19,04\%), aparecen también el pago de cánones para aparecer en la prensa (14,28\%), y hacen referencia a los aspectos no deportivos que ocupan el poco espacio mediático existente y que les roba espacio a las mujeres (14,28\%), así como la utilización política del deporte $(4,75 \%)$.

\section{Omnipresencia del fútbol}

Las deportistas entrevistadas observan una programación deportiva centrada en el fútbol, incluso van más allá, y dicen que hay demasiado fútbol, exponen la dificultad de encontrar otros deportes en la programación.

Tú ves hoy en día el periódico AS, por ejemplo, lo miré ayer e intentaba buscar alguna noticia del periódico que no fuera de fútbol y no vi ninguna. Ese periódico, en vez de ser de deportes debería ser solo de fútbol. No me parece mal que haya un periódico que sea solo de fútbol. Pero ique en un periódico general un deporte lo pongan todo el rato! (160404_E16)

El fútbol, a pesar de lo que podrían desear algunas entrevistadas, ocupa la mayor parte de los informativos deportivos, a costa de otros deportes (algunas de las deportistas expresan que no les gusta que se hable de deportes minoritarios, en su lugar, prefieren decir menos visibilizados, o con menor seguimiento).

Yo creo que vemos demasiado fútbol, pero claro, es que yo soy de deportes minoritarios iQué voy a decir! A mí me parece que hay demasiado fútbol y muy poco de otros deportes. (160405_E9)

Deportes menos visibilizados ocupan escasos espacios en la prensa o no aparecen a pesar de los resultados en Campeonatos Mundiales. La programación deportiva actual no se organiza en función a méritos deportivos, sino en deportes concretos. 
Me parece que cuando, ahora mismo ha ganado el chico este, que ha ganado la de oro', ese chico tendría que salir antes del fútbol y antes de todo. (160404_E8)

Algunas deportistas entran a valorar las horas de entrenamiento de los diferentes deportes y por esta razón piensan que el fútbol se valora en exceso, señalan que es necesario apreciar también el esfuerzo en otros deportes.

Creo que al fútbol en España se le da demasiada importancia para lo que yo creo que entrenan, pero yo sé, por ejemplo, en entrevistas que he leído lo que entrena Mireia ${ }^{2}$ y es una burrada, son diferentes deportes está claro, pero el valor se lo tienen que dar a todas las cosas. (160404_E16)

Como alternativa a esta realidad, proponen una programación vinculada a los logros deportivos en lugar de deportes concretos.

\section{Aspectos no deportivos de ellos restan espacio a méritos de ellas}

Ellas observan un trato desigual e incluso cierto desprecio de sus prácticas y éxitos. Ellas son conscientes de que las carreras deportivas de ellos tienen gran eco mediático, mientras que las suyas apenas consiguen aparecer. La mayoría de ellas asume que el seguimiento mediático de sus carreras deportivas nada tiene que ver con el de sus compañeros. "No, igualitario no es, siempre se le quita como importancia a lo nuestro." (160406_E15)

Cualquier detalle de la vida de los deportistas se antepone a las carreras deportivas de ellas. En el caso de ellos, se ensalzan primero sus triunfos, y luego algunos periodistas se permiten hablar de otros detalles lejanos al deporte. En el caso de ellas, ese orden no siempre se mantiene, se realizan comentarios poco profesionales y muy estereotipados de sus carreras, quitándole valor a lo propiamente deportivo.

$Y$ es verdad que, en deporte femenino, muchas veces se alude a temas extradeportivos, dándole prioridad a eso secundario más que a lo que se ha conseguido; cuando en chicos es al revés, primero ponen lo que ha conseguido y luego si toca, hablo del peinado de Cristiano ${ }^{3}$. Pero lo primero es que ha metido tres goles en el partido. (160325_E11)

En estos momentos hablan de que la programación deportiva es monocolor, hay casi un único deporte y el resto apenas aparece. Cuesta encontrar en las páginas de los periódicos deportivos noticias de especialidades deportivas menos visibilizadas. Algunos deportistas de esas especialidades únicamente consiguen huecos en la programación deportiva tras grandes éxitos mundiales.

\section{Lucha de ellas: Resistencia}

En la presente categoría se menciona la ausencia de las mujeres deportistas en la programación y la difamación que se hace de sus carreras, ante lo que ellas muestran su resistencia (33.33\% de las referencias están relacionadas con esta categoría).

\section{Ausencia de las deportistas en la programación}

Las mujeres deportistas expresan que tan solo ocupan unos pocos minutos en una prensa deportiva sexista a la que solo acceden si consiguen grandes triunfos.

Cuesta encontrar programas deportivos en los que ellas sean las protagonistas, no hay un seguimiento de sus competiciones y cuando salen en los medios es porque sus logros las avalan, A pesar de sus logros, se tienen que conformar aún con una presencia fugaz en los medios.

Ya no les sirve de nada decir que las mujeres no son buenas, que no hacen deporte, que no consiguen medallas. Las últimas competiciones, especialmente las olimpiadas han demostrado todo lo contrario, pero este hecho no parece ser suficiente para cambiar la realidad de la programación deportiva. ¿Por qué no sale ninguna mujer?, ¿qué pasa con todos los éxitos que ha habido? Han sido de mujeres ¿cómo es que no salen? (160501_E17)

Hay deportes casi invisibles de los que no aparecen noticias ni triunfos ni de unos ni de otras. Deportes como el waterpolo, patinaje artístico o la gimnasia rítmica deportiva aparecen esporádicamente en las programaciones deportivas, normalmente cuando el equipo nacional tiene alguna posibilidad de triunfo. Pero en muchos deportes los triunfos no son aval suficiente para que las deportistas logren espacio en las programaciones deportivas actuales, algunas ausencias han sido especialmente denunciadas.

' Javier Fernández acababa de ganar la medalla de oro en el campeonato del mundo de Boston de patinaje sobre el hielo en 2016.

${ }^{2}$ Se refiere a Mireia Belmonte, nadadora, ganadora de 1 oro y 1 bronce en los JJOO de Río y de dos medallas de plata en los JJOO de Londres.

${ }^{3}$ Se refiere a Cristiano Ronaldo, en ese momento jugador del Real Madrid de fútbol. 
Pues porque me parece que ganar una medalla de oro es algo importante, porque en waterpolo de chicas que no salieron cuando ganaron no sé qué, las gimnastas, ... todas. (160404_E8)

No aparecen y cuando lo hacen el lugar que ocupan es tan escaso que cuesta apreciarlo. La programación deportiva, normalmente centrada en las competiciones también difunde los recibimientos de los deportistas, algunas veces también de las deportistas, sin embargo, los triunfos de unos y otras no son publicados de la misma manera, a ellas les dedican apenas unos segundos, incluso tras importantes éxitos como puedan ser las olimpiadas.

Cuando he ganado una medalla de bronce en Brasil y estoy llegando al aeropuerto y si hay cámaras igual grabándote, pues igual, pero... que te graben media hora y que veas que luego sales dos segundos, dos segundos en los que no te da ni tiempo a verlo. (160404_E8)

Ellas se lamentan de esta realidad que las maltrata, quitando trascendencia a sus carreras deportivas, y ningunea sus triunfos. Frente a la actitud de determinados periodistas que mencionan que el deporte femenino no es atractivo, algunas de ellas defienden el interés de los deportes practicados por mujeres, y los consideran más atractivos por diferentes razones:

Yo el balonmano masculino y el femenino los veo muy diferentes. Yo he tenido mucha gente a mi alrededor que me ha llegado a decir que le gusta más el balonmano femenino. Y a mí me gusta más el balonmano femenino. Yo creo que el nuestro es más bonito pues porque no prevalece tanto la fuerza, la gente se mueve sin balón, somos más rápidas, más tácticas. A mí me encanta. (160404_E8)

Algunas deportistas sugieren que algunos deportes tienen mayor interés cuando los practican ellas, a pesar de lo que dice la prensa.

\section{Difamación deportiva}

Algunas cadenas emiten programas específicos sobre operaciones antidopaje que reflejan una realidad parcial de deportes concretos. Esos deportes sufren así duras críticas y se divulga una imagen bastante negativa que no ayuda a la difusión de su práctica y que oculta el verdadero esfuerzo de los y las deportistas.

Sí, pues sinceramente, pues demostrando que no es todo doping, que no son todo accidentes, que hay muchísima gente que lo practicamos. Demostrando que, no es tan negro como se está diciendo, que detrás de todo eso hay valores. (160331_E13)

La ausencia en la prensa está provocada por las características de algunos medios concretos, por la intención de invisibilizar el deporte femenino y sus logros, por los cánones establecidos a diferentes medios de comunicación, por la omnipresencia del fútbol y por el hecho de que aspectos no deportivos de los deportistas resten espacio a los triunfos de ellas.

\section{Visibilidad de ellas: Agencia}

Según las expresiones recogidas de las personas entrevistadas, la visibilidad de ellas se ha conseguido en los casos en los que ellas se han empoderado, en los casos en los que ellas son agencia. Aprecian también un cambio y una ligera apertura que se ha dado en los últimos tiempos, siendo mayor su visibilidad en las Olimpiadas (el $14,28 \%$ de las referencias realizadas durante las entrevistas se relaciona con esta categoría).

\section{Las futbolistas también omnipresentes en la programación}

El actual modelo de prensa deportiva centrada en los hombres relega a las mujeres a posiciones menos importantes, pero entre las deportistas también hay diferencias, precisamente las mismas que existen entre ellos.

$Y$ luego pues eso en ETB que casi todos los domingos que jugamos en Lezama dan los goles $y$ ijo!, pues eso da alegría y dices: iJo, aunque me pongan la última en los deportes!, pero te ponen. Y creo que eso debería ser en todas las cadenas y no solo en ETB4. (160324_E12)

La aparición de nuevas cadenas de televisión está cambiando el panorama, pero son algunos medios especialmente los que han dado seguimiento a partidos de equipos femeninos.

...para salir en la tele tienes muchos canales más ahora, por ejemplo, en Bein Sport sacan los partidos, pero hace años yo solo recuerdo que salían las chicas en ETB y solo el Atlhetic, pero igual te ponías a ver la televisión en Madrid y no veías ni un partido de fútbol femenino porque no lo daban. Aquí sí, en ETB lo llevan dando muchos años. (160324_E12)

Una de las futbolistas entrevistadas piensa que la prensa de Euskadi puede suponer un referente en cuanto a fútbol femenino con respecto a otras comunidades autónomas, ya que percibe que hay un trato más adecuado hacia el deporte femenino.

${ }^{4}$ ETB es la televisión pública autonómica vasca. 
Yo creo que a nosotras sí nos valoran y mucho. Todas las veces que salimos en la revista, o a mí, por ejemplo, me llaman de la radio y siempre están muy interesados y están informados. En las portadas, en la prensa cuando salimos, creo que el trato siempre es bueno, cuando se habla de nosotras se habla bien. Estoy hablando de Euskadi que para mí es un referente en cuanto a fútbol femenino que es lo que yo vivo. Sé que en la radio muchas veces ponen a chicas de hockey $y$ siguen muchos deportes femeninos. $Y$ creo que es un referente $y$ que en todas las comunidades debería de ser así. (160324_E12)

En el formato de prensa deportiva con mujeres protagonistas se reproduce el formato masculino; si en las noticias deportivas el fútbol ocupa la mayor parte del tiempo, las futbolistas son también las deportistas con más minutos. Canales tradicionales difunden sus carreras deportivas y las nuevas cadenas refuerzan el trabajo de difusión realizado hasta ahora por las televisiones autonómicas.

\section{Apertura en la programación}

La programación deportiva comienza a tener en cuenta el deporte practicado por ellas, la igualdad queda lejos y aunque se observa cierta resignación, las perspectivas parecen favorables.

Yo creo que peor de lo que hemos estado no se puede estar, porque hace muchos años, yo hace diez años veía esto bastante peor que ahora. Creo que todo lo que venga va a ser para mejorar. Nosotras, por ejemplo, antes no nos televisaban ningún partido y los de chicos los televisaban. Ahora televisan los de chicas y los de chicos. Igual todavía hay una pequeña diferencia, porque televisan los pequeños torneos de chicos y no los de chicas, pero se va equiparando. (160404_E8)

Observan cambios en la programación deportiva, ven un avance respecto a años atrás, alguna de ellas se muestra esperanzada sobre la situación de la mujer en la prensa deportiva.

\section{Olimpiadas}

Las personas entrevistadas opinan que la programación deportiva parece tener su mayor exponente durante las Olimpiadas. Hay más horas de programación deportiva, un seguimiento mayor y más exhaustivo de los diferentes deportes y mayor variedad. Los JJOO suponen un punto de inflexión, ya que se suceden diferentes competiciones deportivas, y en algunas de las finales participan deportistas nacionales femeninas. Ese hecho, haber llegado a unas olimpiadas y competir por una medalla, favorece el seguimiento de ese deporte y en algunos casos, convierte a sus protagonistas en figuras mediáticas. Me parece que las guerreras ${ }^{5}$ han enganchado al público cuando han jugado unos JJOO y les
han televisado... Y yo pongo de ejemplo a mi hermana, mi hermana ahora tiene no sé cuántos
mil seguidores en Twitter porque le han televisado en unos JJOO, han ganado una medalla, y
la gente ha podido verla en la tele y se han enganchado, pero hasta entonces... Hay jugadoras
que han jugado hace 15 años que no les han sacado nunca, la gente no sabe ni quiénes son.
(160404_E8)

Las Olimpiadas suponen un hecho excepcional gracias al cual es posible ver partidos o competiciones de modalidades poco habituales en la programación deportiva. Suponen la aparición de deportistas que gracias a sus clasificaciones y récords consiguen un hueco en las cadenas de televisión y se convierten así en figuras mediáticas.

Hoy en día "Las Guerreras" son la bomba, pero porque en los JJOO les han televisado, y han enganchado, Teledeporte ha retrasmitido sus partidos y la gente se ha enganchado. Pero yo creo que los medios de comunicación hasta hace muy poco te hacían caso cuando ganabas, cuando no ganabas... O sea que como mujer yo me he sentido que muchas veces que he tenido que conseguir títulos para conseguir que te televisen... (160404_E8)

Las carreras deportivas de ellas, tal como afirma esta última deportista, son más difíciles, dependen de sus logros para conseguir apoyo por parte de la publicidad y de los medios de comunicación.

\section{Discusión y conclusiones}

En relación con el primer objetivo, la percepción que tienen las entrevistadas sobre la presencia de las mujeres en la escena mediática coincide con los análisis culturales que apuntan tres fases en la aparición de las mujeres a la escena pública (SHOWALTER, 1977; MURGUIALDAY, 2013). Así, en primer lugar, ellas perciben un paisaje masculino y androcéntrico en la programación deportiva; en segundo lugar, refieren la lucha de ellas por transitar desde la invisibilidad a la visibilidad; y por último, señalan una tercera dimensión donde la visibilidad y el empoderamiento de las mujeres deportistas emerge tímidamente en la programación deportiva.

${ }^{5}$ Las mujeres de la selección española de balonmano fueron apeladas de ese modo por la prensa tras conseguir una medalla de bronce en el mundial previo a los JJOO de Londres 2012. 
Concluimos así que las reglas de juego que se imponen en la programación deportiva contribuyen a visibilizar el deporte masculino. Por lo tanto, existe un poder visible (LUKES, 1974) que favorece la hegemonía del deporte masculino. Este poder visible también se manifiesta como un poder oculto que vuelve invisibles a las voces subalternas (SPIVAK, 1993) mediante la desinformación o la selección de la programación deportiva, donde ellas apenas tienen lugar porque la programación deportiva está centralizada en un único deporte, el fútbol (ANGULO, 2007; IRAZUSTA et al., 2010; SAINZ DE BARANDA, 2013). El 52,38\% de las entrevistadas argumenta que los deportistas masculinos son el centro de casi todos los programas deportivos.

En relación con el poder oculto, el $28,57 \%$ de las entrevistadas señala la ausencia de las deportistas en la programación y el 4,76\% lamenta la difamación, así las campañas de desprestigio que difunden medios concretos sobre algunas modalidades deportivas vinculadas con casos de dopaje (ASPIC, 2013; KIRK; OLIVER, 2014).

En relación con el segundo objetivo, es decir, a la percepción del empoderamiento ejercido por ellas, se concluye que la visibilidad hegemónicamente masculina ha desafiado las relaciones de poder existentes con el deporte femenino, y la resistencia de ellas ha contribuido a la apertura de la programación y a la negociación del poder. El 7,14\% de las deportistas entrevistadas observa una apertura de la programación con respecto a años atrás, así similares datos ya han sido recogidos en anteriores investigaciones (ALFARO et al., 2011).

Desde una lectura feminista esta apertura proyecta la capacidad de resistencia y transformación del poder controlador o de dominación que se consigue a través de la agencia (ORTNER, 2006; ESTEBAN, 201 1). Las mujeres deportistas como agentes individuales y como colectivo con capacidades y competencias no necesitan ser salvadas por otras personas ni otras instituciones, porque ellas, en función de su resistencia y los logros, han visibilizado su labor. Han sido invisibilizadas y sus éxitos no se han correspondido con el espacio logrado en los medios y no ha sido suficiente que las mujeres hayan sido buenas y hayan ganado medallas (VEGA; AVALOS, 2016).

Si en algún momento se ha requerido que la apertura de la programación deportiva se realice con el deporte femenino, es debido a la agencia adquirida por las mujeres deportista; el poder interno (MURGUIALDAY, 2013) y a la identidad colectiva (MOSEDALE, 2005) que ellas mismas han construido en esa misma línea al señalar las injusticias, la desigualdad y al crear su propio discurso al realizar continuamente preguntas como "¿Qué pasa con todos los éxitos que ha habido?" A modo de respuesta y como conclusión del artículo, hay que señalar que las voces de las entrevistadas dibujan cartografías de resistencia y agencia que se articulan como lucha y visibilidad en este estudio. Esta visibilidad tímida del deporte femenino revela una negociación creativa y transformadora con los poderes hegemónicos que regentan y mediatizan la programación deportiva, y es que como ellas afirman, el deporte femenino tiene algo muy interesante para el público: es un paradigma donde no solo prevalece la fuerza. Un paradigma donde se ve ese tránsito del androcentrismo a una realidad andrógina que contribuya a la dilución de los géneros (Miguel VICENTE-PEDRAZ; María Paz BROZAS-POLO, 2017) para que ellos puedan aprender, ya que ellas, además de resistir y adquirir agencia, han aprendido mucho de los deportes masculinos. Ahora les toca a ellos aprender (Marina SUBIRATS, 2011).

\section{Referencias}

ALFARO, Elida et al. Deporte y mujeres en los Medios de Comunicación. Sugerencias y recomendaciones. Madrid: CSD, 2011.

ANGULO, Marta. Las imágenes de las deportistas en los medios de comunicación. Madrid: Ministerio de Educación y Ciencia, 2007.

ASPIC Asesoría. Presencia y tratamiento del deporte femenino en la prensa generalista vasca y en periódicos de información deportiva. Vitoria-Gasteiz: Eusko Jaurlaritza/Gobierno Vasco, 2013.

AZURMENDI, Ainhoa; MURUA, Juan. Estudio desde la perspectiva de género sobre la situación de las deportistas de alto nivel de la CAPV. Vitoria-Gasteiz: Eusko Jaurlaritza/Gobierno Vasco, 2010.

BARBOUR, Rosaline. Los grupos de discusión en Investigación Cualitativa. Madrid: Morata, 2013.

BASQUETEAM. Estatutos. Getxo: Fundación Euskadi Kirola Fundazioa, 2019.

BERNESTEIN, Alina. "Is it time for a victory lap? Changes in the media coverage of women in sport". International Review for the Sociology of Sport, Brighton (UK), v. 37, n. 3-4, p. 415-428, diciembre 2002.

BLANDÓN, María Teresa; MURGUIALDAY, Clara; VAZQUEZ, Norma. Los cuerpos del feminismo nicaragüense. Managua: Programa Feminista La Corriente, 2011. 
BOURDIEU, Pierre. La dominación masculina. Barcelona: Anagrama, 2000.

DEPARTAMENTO DE CULTURA DE GOBIERNO VASCO. Memoria del Departamento de Cultura del Gobierno Vasco 2009-2010. Vitoria-Gasteiz: Servicio central de publicaciones del Gobierno Vasco, 2012. Disponible en http://www.kultura.ejgv.euskadi.eus/r46-714/es/contenidos/noticia/ memorias_2009_2010/es_memorias/noticia.html.

EMAKUNDE. VII Plan para la Igualdad de Hombres y Mujeres en la CAE (2018-2021). Vitoria-Gasteiz: Eusko Jaurlaritza/Gobierno Vasco, 2018. Disponible en http://www.euskadi.eus/plan-gubernamental/ 02-vi-plan-para-la-igualdad-de-mujeres-y-hombres-en-la-capv/web01-s2lehen/es/.

ESTEBAN, María Luz. "Cuerpos y políticas feministas: el feminismo como cuerpo". In: VILLALBA, Cristina; ÁlVAREZ LUCENA, Nacho. Cuerpos Políticos y Agencia. Granada: Universidad de Granada, 2011. p. 9-21.

FERNÁNDEZ, Mercedes. Escuela de Empoderamiento para las Mujeres. Nuevas experiencias de formación y transformación feminista en la sociedad vasca. (Trabajo fin de máster sin publicar). Bilbao: Universidad del País Vasco (EHU/UPV), 2012.

FERNÁNDEZ, Mercedes. Filosofía y debates feministas. In: MUNDIALIZACIÓN Y LIBERACIÓN. II ENCUENTRO MESOAMERICANO DE FILOSOFÍA, 1996, Managua. Managua: UCA, 1996. p. 297-310.

FERNANDEZ-LASA, Uxue. Emakume pilotariak: izaera, bizipen eta sentipenak. (Tesis doctoral). VitoriaGasteiz: Universidad del País Vasco (EHU/UPV), 2014.

FOUCAULT, Michel. The Archaeology of Knowledge. New York: Pantheon, 1972.

FREIRE, Paulo. La pedagogía del oprimido. Méjico: Siglo XXI, 1986.

GALLEGO, Joana; ALTÉS, Elvira; MELÚS, María Elvira; SORIANO, Jaume; CANTÓN, María José. "La prensa diaria por dentro: mecanismos de transmisión de estereotipos de género en la prensa de información general". Anàlisis, Quaderns de investigació l cuktura, Barcelona, v. 28, p. 225-242, mayo/junio, 2002.

GUERRERO, Susana. La prensa deportiva española. Sexismo lingüístico y discursivo. Córdoba: UCO Press, 2017.

GRAMSCI, Antonio. Selections from the Prison Notebooks. Londres: Lawrence and Wishat, 1971.

IRAZUSTA, Susana; ETXEBARRIA, Juan; AZURMENDI, Ainhoa; GARAY, Beatriz; EGIBAR, Miren. "Impacto mediático de las deportistas de élite guipuzcoanas". In: MARTINEZ DE ALDAMA, Inma; CAYERO, Ruth; CALLEJA, Julio (coord.). Investigación e innovación en el deporte. Barcelona: Paidotribo, 2012. p. $110-117$.

HERRÁNZ, Yolanda. Igualdad bajo sospecha. El poder transformador de la educación. Madrid: Narcea, 2006.

JULIANO, Dolores. El juego de las astucias: mujer y construcción de modelos sociales alternativos. Madrid: Horas y Horas, 1992.

JULIANO, Dolores. Las que saben. Subculturas femeninas. Madrid: Horas y Horas, 1998.

KABEER, Naila. "Empoderamiento desde abajo. ¿Qué podemos aprender de las organizaciones de base?". In: LEÓN, Magdalena (coord.). Poder y empoderamiento de las mujeres. Bogotá: Tercer Mundo, 1997. p. 119-146.

KABEER, Naila. "Resources, agency, achievements: Reflections on the measurement of women's empowerment". Development and Change, Oxford, v. 30, n. 3, p. 435-464, mayo, 1999.

KIRK, David; OLIVER, Kimberly. "La misma historia de siempre: reproducción y reciclaje del discurso dominante en la investigación sobre la educación física de las chicas". Apunts. Educación Física y Deportes, Barcelona, v. 11 16, n. 2, p. 7-22, junio 2014.

KVALE, Steinar. Las entrevistas en Investigación Cualitativa. Madrid: Morata, 2012.

LALLANA, Ibone. "La influencia de los medios de comunicación en el rendimiento deportivo femenino. El refuerzo de los estereotipos sociales". In: LARRONDO, Ainara; MESO, Koldo. IV Jornadas Mujer $y$ Medios de Comunicación. Bilbao: Universidad del País Vasco (UPV/EHU), 2012. p. 99-108. 
LEÓN, Magdalena. Poder y empoderamiento de las mujeres. Bogotá: Tercer Mundo Editores, 1997.

LEY 4/2005, de 18 de febrero, para la Igualdad de Mujeres y Hombres, BOPV núm. 42 de 02 de marzo de 2005 y BOE núm. 274 de 14 de noviembre de 2011.

LÓPEZ, Pilar. "20 informe de la investigación: Representación de género en los medios informativos de radio y televisión". Madrid: Instituto Oficial de Radio y Televisión, 2005.

LÓPEZ, María. José. Mujer, discriminación y deporte. Madrid: Editorial Reus, 2017.

LUKES, Steven. Power. A radical view. Londres: Macmillan, 1974.

MARÍN, María Flora; GANZABAL, María. "La mujer (in)visible: la construcción de la identidad femenina a través de la fotografía en El País y El Mundo". Enl@ce Revista Venezolana de Información, Tecnología y Conocimiento, Maracaibo, v. 8, n. 3, p. 51-67, septiembre/diciembre 2011.

MARUGÁN, Begoña. "El deporte como bastión del machismo". In: NÚÑEZ, Trinidad; MíGUEZ Araceli (Coords.). Re-creando imaginarios. Seminario internacional: Actas Cine, deporte y género. Sevilla: Ayuntamiento de Sevilla, 2017. p. 30-39.

MÁS, Mar. "Asociación para Mujeres en el Deporte Profesional, AMDP". In: MARUGÁN, Begoña (Eds.). El deporte femenino, ese gran desconocido. Madrid: Instituto de Estudios de Género, Universidad Carlos III, 2019. p. 187-201.

MOSEDALE, Sarah. "Assessing women's empowerment: towards a conceptual framework". Journal of international development, Manchester, v. 17, n. 2, p. 243-257, febrero 2005.

MURGUIALDAY, Clara. "Empoderamiento de las mujeres: conceptualización y estrategias.", 2006. Disponible en http://www.vitoria-gasteiz.org/wb021/http/contenidosEstaticos/adjuntos/es/16/23/ 51623.pdf.

MURGUIALDAY, Clara. Reflexiones feministas sobre el empoderamiento de las mujeres. Barcelona: Colección Cooperació. Agencia Catalana de Cooperació al Desenvolupament, 2013.

OAKLEY, Peter. Evaluating Empowerment: Reviewing the Concept and Practice. Oxford: INTRAC, 2001.

ORTNER, Sherry. Anthropology and Social Theory: Culture, Power, and the Acting Subject. Durham, NC: Duke University Press, 2006.

PÉREZ SERRANO, María Gloria. Investigación cualitativa: retos e interrogantes. Madrid: La Muralla, 2014.

ROBLES, Fe. "Asociacionismo en el deporte". In: MARUGÁN, Begoña. (Ed). El deporte femenino, ese gran desconocido. Madrid: Instituto de Estudios de Género, Universidad Carlos III, 2019. p.179186.

ROJAS, José Luis. "La construcción de las noticias deportivas desde una mirada androcéntrica. De la invisibilidad a los estereotipos de la mujer deportista". Vivat Academia, Madrid, v. 113, p. 122136, diciembre 2010.

SAINZ DE BARANDA, Clara. Mujeres y deporte en los medios de comunicación. Estudio de la prensa deportiva española (1979-2010). Disertación doctoral. Madrid: Universidad Carlos III, 2013.

SANZ, Begoña. Las mujeres deportistas en la prensa: los Juegos Olímpicos de Londres 2012. Barcelona: Editorial UOC, 2015.

SHOWALTER, Elaine. A Literature of Their Own. British Women Novelits from Brontë to Lessing. Londres: Virago, 1977.

SPIVAK, Gayatri Chakravorty. "Can the subaltern speak?" In: WILLIAMS, Patrick; CHRISMAN, Laura. Colonial Discourse and Post-colonial Theory: A Reader. Londres: Harvester Wheatsheaf, 1993. p. 66-11.

STAKE, Robert E. Multiple Case Study Analysis. New York: Guilford Press, 2005.

SUBIRATS MARTÒRI, Marina. "Igualdad de sexos, desigualdad de géneros". Tiempo de paz, Madrid, v. 100, p. 183-187, 2011. 
VEGA, Lilian; AVALOS, María Alejandra. "La presencia de la mujer deportista en televisión". Feminismo/ s, Alicante, v. 27, p. 165-175, junio 2016. Disponible en https://rua.ua.es/dspace/bitstream/10045/ 61253/1/Feminismos_27_09.pdf. Consulta realizada 26/06/18.

VICENTE-PEDRAZ, Miguel; BROZAS-POLO, María Paz. "Sexo y género en la contienda identitaria del deporte. Propuesta de un debate sobre la competición deportiva multigénero". Cultura, ciencia y deporte: revista de ciencias de la actividad física y del deporte de la Universidad Católica de San Antonio, n. 35, p. 101-110, 2017.

VIZCARRA, María Teresa; MACAZAGA, Ana María; REKALDE, Itziar. Las necesidades y valores de las niñas ante la competición escolar. Bilbao: Emakunde y UPV/EHU, 2009.

WOOD, Phil; SMITH, Joan. Investigar en educación. Conceptos básicos y metodología para desarrollar proyectos de investigación. Madrid: Narcea, 2018.

Judit Martínez Abajo (juditmaab@hotmail.com) es profesora laboral interina del Departamento de Didáctica de la Expresión Musical, Plástica y Corporal. Doctora en Filosofía Ciencias de la Educación. Licenciada en Educación Física y diplomada como maestra de Educación Primaria y como maestra Educación Infantil. Grupo de investigación Gobierno Vasco IT1304-19 IKHezi, línea de investigación: investigación educativa y estudios de género.

Gema Lasarte Leonet (barinborda@gmail.com) es Profesora Agregada del Departamento de Didáctica de la Lengua y la Literatura. Doctora en Ciencias Literarias y licenciada en Ciencias de la Información. Grupo de investigación Gobierno Vasco IT1304-19 IKHezi, línea de investigación: investigación educativa y estudios de género.

Rakel Gamito Gomez (rakel.gamito@gmail.com) es profesora laboral interina en el Departamento de Didáctica y Organización Escolar. Doctora en Filosofía Ciencias de la Educación y graduada en Educación Infantil. Grupo de investigación Gobierno Vasco IT1304-19 IKHezi, línea de investigación: investigación educativa y estudios de género.

María Teresa Vizcarra Morales (mariate.bizkarra@gmail.com) es Profesora Titular de Universidad del Departamento de Didáctica de la Expresión Musical, Plástica y Corporal. Doctora en Filosofía Ciencias de la Educación y licenciada en Educación Física. Grupo de investigación Gobierno Vasco IT1304-19 IKHezi, línea de investigación: investigación educativa y estudios de género.

\section{COMO CITAR ESTE ARTíCULO, DE ACUERDO CON LAS NORMAS DE LA REVISTA:}

ABAJO, Judit Martínez; LEONET, Gema Lasarte; GOMEZ, Rakel Gamito; MORALES, María Teresa Vizcarra. "Sports Programming, what Place do Women Occupy?". Revista Estudios Feministas, Florianópolis, v. 28, n. 2, e60585, 2020.

\section{CONTRIBUCIÓN DE AUTORÍA}

Judit Martínez Abajo: concepción, recolección de datos y análisis de datos, elaboración del manuscrito, redacción, discusión de resultados.

Gema Lasarte Leonet: concepción, recolección de datos y análisis de datos, elaboración del manuscrito, redacción, discusión de resultados.

Rakel Gamito Gomez: elaboración del manuscrito, redacción, discusión de resultados.

María Teresa Vizcarra Morales: concepción, recolección de datos y análisis de datos, elaboración del manuscrito, redacción, discusión de resultados.

FINANCIACIÓN

No se aplica.

CONSENTIMIENTO DE USO DE IMAGEN

No se aplica. 


\section{APROBACIÓN DE COMITÉ DE ÉTICA EN INVESTIGACIÓN}

No se aplica.

\section{CONFLICTO DE INTERESES}

No se aplica.

\section{LICENCIA DE USO}

Este artículo está licenciado bajo la Licencia Creative Commons CC-BY Internacional. Con esta licencia se puede compartir, adaptar, crear material para cualquier objetivo, siempre que se le atribuya la autoría.

\section{HISTORIAL}

Recibido el 06/12/2018

Presentado nuevamente el 30/11/2019

Aprobado el 07/02/2020 